Review

\title{
Recent Photocatalytic Applications for Air Purification in Belgium
}

\author{
Elia Boonen* and Anne Beeldens \\ Belgian Road Research Center (BRRC), Woluwedal 42, 1200 Brussels, Belgium; \\ E-Mail: a.beeldens@brrc.be \\ * Author to whom correspondence should be addressed; E-Mail: e.boonen@brrc.be; \\ Tel.: +32-2-766-03-41; Fax: +32-2-767-17-80.
}

Received: 23 May 2014; in revised form: 18 July 2014 / Accepted: 24 July 2014 /

Published: 31 July 2014

\begin{abstract}
Photocatalytic concrete constitutes a promising technique to reduce a number of air contaminants such as $\mathrm{NO}_{x}$ and VOC's, especially at sites with a high level of pollution: highly trafficked canyon streets, road tunnels, the urban environment, etc. Ideally, the photocatalyst, titanium dioxide, is introduced in the top layer of the concrete pavement for best results. In addition, the combination of $\mathrm{TiO}_{2}$ with cement-based products offers some synergistic advantages, as the reaction products can be adsorbed at the surface and subsequently be washed away by rain. A first application has been studied by the Belgian Road Research Center (BRRC) on the side roads of a main entrance axis in Antwerp with the installation of $10.000 \mathrm{~m}^{2}$ of photocatalytic concrete paving blocks. For now however, the translation of laboratory testing towards results in situ remains critical of demonstrating the effectiveness in large scale applications. Moreover, the durability of the air cleaning characteristic with time remains challenging for application in concrete roads. From this perspective, several new trial applications have been initiated in Belgium in recent years to assess the "real life" behavior, including a field site set up in the Leopold II tunnel of Brussels and the construction of new photocatalytic pavements on industrial zones in the cities of Wijnegem and Lier (province of Antwerp). This paper first gives a short overview of the photocatalytic principle applied in concrete, to continue with some main results of the laboratory research recognizing the important parameters that come into play. In addition, some of the methods and results, obtained for the existing application in Antwerp (2005) and during the implementation of the new realizations in Wijnegem and Lier (2010-2012) and in Brussels (2011-2013), will be presented.
\end{abstract}


Keywords: $\mathrm{TiO}_{2}$; photocatalysis; concrete pavements; air purification; nitrogen oxides surface treatment

\section{Introduction}

Emission from the transport sector has a particular impact on the overall air quality because of its rapid rate of growth: goods transport by road in Europe (EU-27) has increased by 31\% (period 1995-2009), while passenger transport by road in the EU-27 has gone up by $21 \%$ and passenger transport in air by $51 \%$ in the same period [1]. The main emissions caused by motor traffic are nitrogen oxides $\left(\mathrm{NO}_{x}\right)$, hydrocarbons $(\mathrm{HC})$ and carbon monoxide $(\mathrm{CO})$, accounting for respectively $46 \%, 50 \%$ and $36 \%$ of all such emissions in Europe in 2008 [2].

These pollutants have an increasing impact on the urban air quality. In addition, photochemical reactions resulting from the action of sunlight on $\mathrm{NO}_{2}$ and VOC's (volatile organic compounds) lead to the formation of "photochemical smog" and ozone, a secondary long-range pollutant, which impacts in rural areas often far from the original emission site. Acid rain is another long-range pollutant influenced by vehicle $\mathrm{NO}_{x}$ emissions and resulting from the transport of $\mathrm{NO}_{x}$, oxidation in the air into $\mathrm{HNO}_{3}$ and finally, precipitation of (acid) $\mathrm{NO}_{3}^{-}$with harmful consequences for building materials (corrosion of the surface) and vegetation.

The European Directives [3] impose a limit to the $\mathrm{NO}_{2}$ concentration in ambient air of maximum $40 \mu \mathrm{g} / \mathrm{m}^{3} \mathrm{NO}_{2}(21 \mathrm{ppbV})$ averaged over 1 year and $200 \mu \mathrm{g} / \mathrm{m}^{3}(106 \mathrm{ppbV})$ averaged over $1 \mathrm{~h}$. These limit values gradually decreased from 50 and 250 in 2005 to the final limit in 2010.

Heterogeneous photocatalysis is a promising method for $\mathrm{NO}_{x}$ abatement. In the presence of UV-light, the photocatalytically active form of $\mathrm{TiO}_{2}$ present at the surface of the material is activated, enabling the abatement of pollutants in the air. The translation from laboratory results to real cases is starting. Different applications are implemented in Belgium in order to see the influence of the photocatalytic materials on real scale and to determine the durability of the air purifying capacity over time.

In the first part of this paper, the principle of photocatalytic concrete will be elaborated, followed by a description of the past laboratory research indicating important influencing factors for the purifying process. Next, an overview of the results regarding the first pilot project in Antwerp [2] is given, and finally, the different applications in Belgium that have recently been finished, will be discussed.

\section{Photocatalytic Concrete: Purifying the Air through the Pavement}

A solution for the air pollution by traffic can be found in the treatment of the pollutants as close to the source as possible. Therefore, photocatalytically active materials can be added to the surface of pavement and building materials [4]. Air purification through heterogeneous photocatalysis consists of different steps: under the influence of UV-light, the photoactive $\mathrm{TiO}_{2}$ at the surface of the material is activated. Subsequently, the pollutants are oxidized due to the presence of the photocatalyst and precipitated on the surface of the material. Finally, they can be removed from the surface by the rain or cleaning/washing with water, see Figure 1. 
Figure 1. Schematic of photocatalytic air purifying pavement.

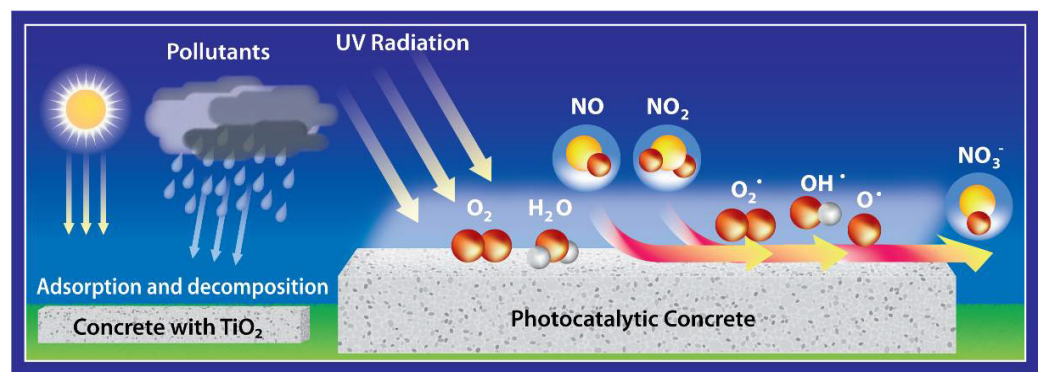

Heterogeneous photocatalysis with titanium dioxide $\left(\mathrm{TiO}_{2}\right)$ as catalyst is a rapidly developing field in environmental engineering, as it has a great potential to cope with the increasing pollution. Besides its self-cleaning properties, it is known since almost 100 years that titanium dioxide acts as a photo-catalyst that can decompose pollutants under UV radiation [5]. The impulse for the more widespread use of $\mathrm{TiO}_{2}$ photocatalytic materials was further given in 1972 by Fujishima and Honda [6], who discovered the hydrolysis of water in the presence of light, by means of a $\mathrm{TiO}_{2}$-anode in a photochemical cell. In the 1980s, organic pollution in water was also decomposed by adding $\mathrm{TiO}_{2}$ and under influence of UV-light [7]. The application of $\mathrm{TiO}_{2}$, in the photo-active crystalline phase anatase, as air purifying material originated in Japan in 1996 (e.g., [8]). Since then, a broad spectrum of products appeared on the market for indoor use as well as for outdoor applications. Regarding traffic emissions, it is important that the exhaust gases stay in contact with the active surface during a certain period. The street configuration, the speed of the traffic, the speed and direction of the wind, all influence the final reduction rate of pollutants in situ.

In the case of concrete pavement blocks $[9,10]$, the anatase is added to the wearing layer of the pavers which is approximately $8 \mathrm{~mm}$ thick. In the case of cast-in-place concrete pavements, the $\mathrm{TiO}_{2}$ is added in the top layer ( $40 \mathrm{~mm}$ thick). The fact that the $\mathrm{TiO}_{2}$ is present over the whole thickness of this layer means that even if some surface wear takes place, for example by traffic or weathering, new $\mathrm{TiO}_{2}$ will be present at the surface to maintain the photocatalytic activity (in contrast to the abrasion of a coating or dispersion layer for instance). The use of $\mathrm{TiO}_{2}$ in combination with cement leads to a transformation of the $\mathrm{NO}_{x}$ into $\mathrm{NO}_{3}^{-}$, which is adsorbed at the surface due to the alkalinity of the concrete [11]. Thus, a synergetic effect is created in the presence of the cement matrix, which helps to effectively trap the reactant gases ( $\mathrm{NO}$ and $\mathrm{NO}_{2}$ ) together with the nitrate salt formed. Subsequently, the deposited nitrate can be washed away by rain or washing with water. In addition, these nitrates pose no real threat towards pollution of body waters because the resulting concentrations in the waste water are very low, even below the current limit values for surface and ground water [12].

Special attention is given here to the $\mathrm{NO}$ and $\mathrm{NO}_{2}$ content in the air, since they are for almost $50 \%$ caused by the exhaust of traffic and are at the base of smog, secondary ozone and acid rain formation as indicated above. The photocatalytic oxidation of NO is usually assumed to be a surface reaction between NO and an oxidizing species formed upon the adsorption of a photon by the photocatalyst, e.g., a hydroxyl radical, both adsorbed at the surface of the photocatalyst [13]. It has been shown by various authors that the final product of the photocatalytic oxidation of $\mathrm{NO}$ in the presence of $\mathrm{TiO}_{2}$ is nitric acid $\left(\mathrm{HNO}_{3}\right)$ while $\mathrm{HNO}_{2}$ and $\mathrm{NO}_{2}$ have been identified as intermediate products in the gas phase over the photocatalyst $[2,4,11,13,14]$. The resulting reaction pathway of the photocatalytic oxidation of NO has been discussed in several publications e.g., $[2,4,13-16]$ most of which proposed the photocatalytic 
conversion of $\mathrm{NO}$ via $\mathrm{HNO}_{2}$ to yield $\mathrm{NO}_{2}$, which is subsequently oxidized by the attack of a hydroxyl radical to the final product $\mathrm{HNO}_{3}$ :

$$
\begin{gathered}
\mathrm{NO}_{\mathrm{ads}}+\mathrm{OH}_{\mathrm{ads}} \rightarrow \mathrm{HNO}_{2 \mathrm{ads}} \\
\mathrm{HNO}_{2 \text { ads }}+\mathrm{OH}_{\mathrm{ads}} \rightarrow \mathrm{NO}_{2 \mathrm{ads}}+\mathrm{H}_{2} \mathrm{O}_{\text {ads }} \\
\mathrm{NO}_{2 \text { ads }}+\mathrm{OH}_{\mathrm{ads}} \rightarrow \mathrm{HNO}_{3 \mathrm{ads}}
\end{gathered}
$$

Here, all nitrogen compounds adsorbed at the photocatalyst surface are assumed to be in equilibrium with the gas phase.

Until now, UV-light (in the UV-A spectrum) was necessary to activate the photocatalyst. However, recent research indicates a shift towards the visible light [17], for instance by doping the $\mathrm{TiO}_{2}$ with transition metal ions or non-metallic anionic species, or forming reduced $\mathrm{TiO}_{x}$. These techniques introduce impurities and defects in the band gap of $\mathrm{TiO}_{2}$ thereby increasing the amount of visible light that can be absorbed and used in the photocatalytic process. This means that applications in tunnels and indoor environments become more realistic. Especially the application in tunnels is worth looking at due to the high concentration of air pollutants at these sites. One of the projects in Belgium is focusing on this subject [18].

\section{Laboratory Results: Parameter Evaluation}

Different test methods have been developed to determine the efficiency of photocatalytic materials towards air purification. An overview is given in [11]. A distinction can be made by the type of air flow; in the flow-through method according to ISO 22197-1 [19], the air, with a concentration of $1 \mathrm{ppmV}$ of $\mathrm{NO}$, passes once-only over the sample which is illuminated by a UV-lamp with light intensity equal to $10 \mathrm{~W} / \mathrm{m}^{2}$ in the range between 300 and $400 \mathrm{~nm}$, as illustrated in Figure 2. Afterwards, the $\mathrm{NO}_{x}(=$ sum of $\mathrm{NO}$ and $\mathrm{NO}_{2}$ ) concentration is measured at the outlet and the reduction (in \%) is calculated. It is also worth to note here that within Europe actions are underway to harmonize and develop new standards for photocatalyis [20]. In any case, the test procedure used for the current results is still based on the existing ISO standard.

Figure 2. (a) Schematic and (b) photo of measurement set-up based on ISO 22197-1:2007 [19] at Belgian Road Research Center (BRRC).

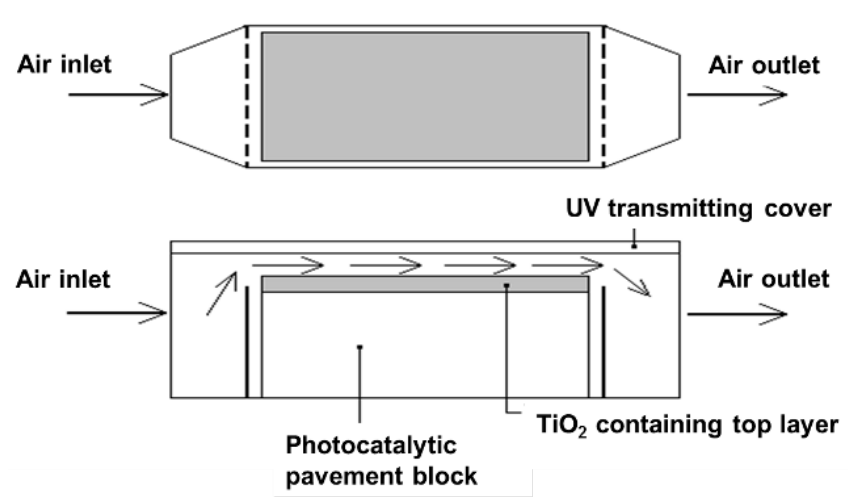

(a)

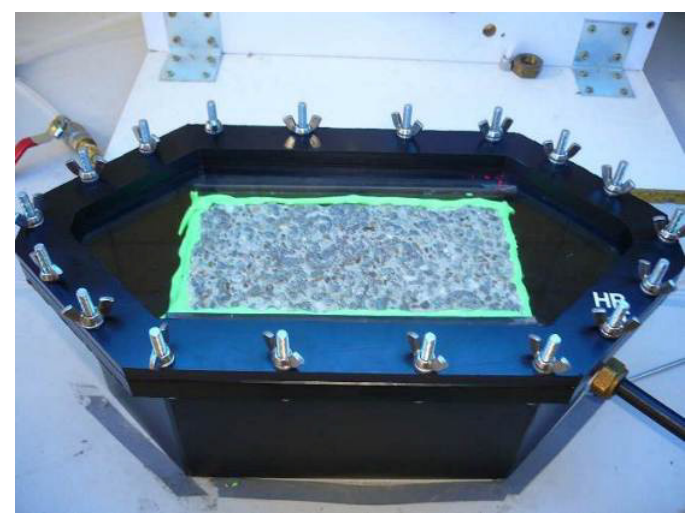

(b) 
The pre-treatment of the samples in the laboratory can be important to obtain reproducible results and mainly depends on the type of base material (e.g., concrete or paints). A typical test scheme according to the ISO standard is presented in Figure 3, where the following steps are applied to the sample: $0.5 \mathrm{~h}$ at $1 \mathrm{ppmV}$ NO concentration, no light $-5 \mathrm{~h}$ exposure to an air flow of $3 \mathrm{~L} / \mathrm{min}$ with $1 \mathrm{ppmV} \mathrm{NO}$ and UV-illumination $-0.5 \mathrm{~h}$ with UV-illumination and no exposure. A small increase with time of the $\mathrm{NO}_{x}$ concentration is visible due to the deposit of the $\mathrm{NO}_{3}^{-}$at the surface.

Figure 3. Typical result obtained in the laboratory following the standard ISO test procedure.

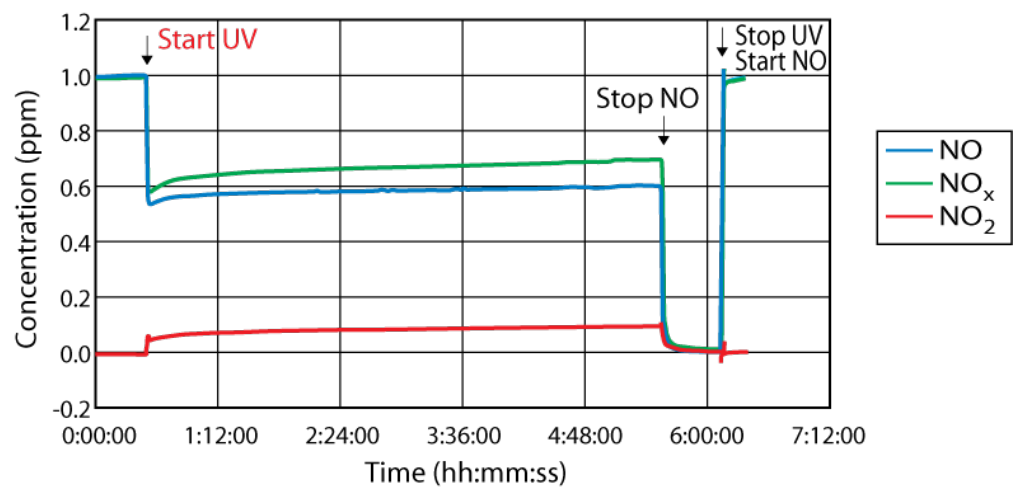

The influence of different important test parameters affecting the photocatalytic reaction has been investigated before [2] such as temperature, light intensity, relative humidity, contact time (controlled by surface area, flow velocity, height of air flow, etc.). For instance, the effect of relative humidity of the ingoing air is illustrated in Figure 4 for different materials including cementitious (concrete, mortar) and other (paint) substrates. Clearly, for cementitious materials the reduction of the $\mathrm{NO}_{x}$ concentration in the outlet air decreases with increasing relative humidity (RH, \%), an observation which was also found by other authors [21]. This probably has to do with the fact that the water in the atmosphere plays a role in the adhesion of the pollutants at the surface and with the competition effect that can arise between water molecules and $\mathrm{NO}_{x}$ in the ambient air with increasing $\mathrm{RH}$. For paints (acidic environment) though, it has been noticed that there is an optimum in RH where a maximal efficiency is obtained. Anyway, relative humidity proves to be an important limiting factor for photocatalytic applications in humid areas like Belgium. Temperature on the other hand, was found to have no significant influence on the $\mathrm{NO}_{x}$ reduction within the ambient range $\left(5-25^{\circ} \mathrm{C}\right)$.

Figure 4. Effect of relative humidity on photocatalytic efficiency for different materials.

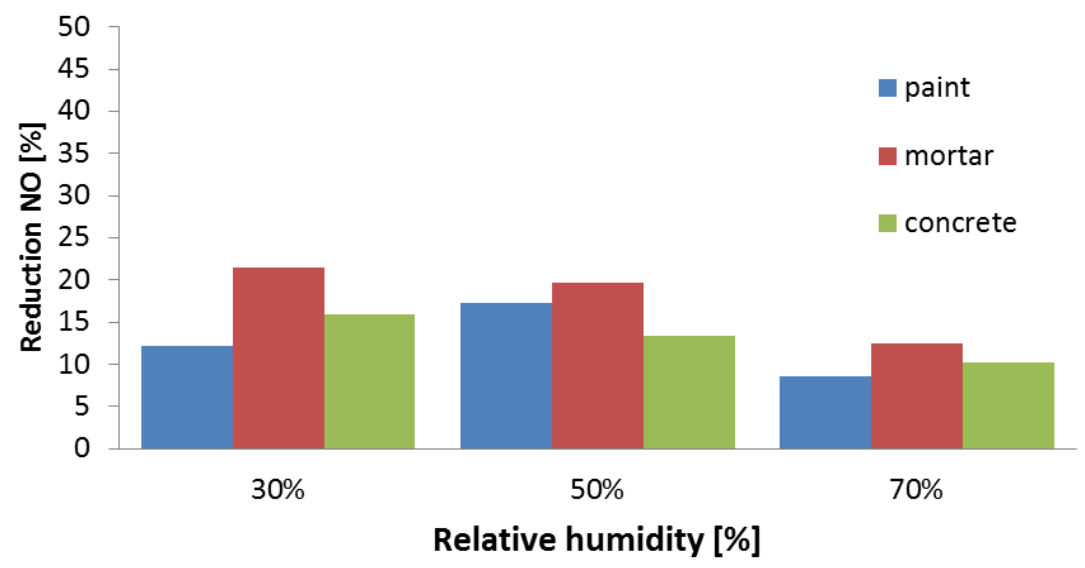


In general, it can be stated that the efficiency towards the reduction of $\mathrm{NO}_{x}$ (in \%) increases with a longer contact time (larger surface area, lower air velocity, smaller height of air flow, higher turbulence at the surface), a lower relative humidity (for cementitious materials) and a higher intensity of incident light. These are the conditions at which the risk of ozone formation in summer is the largest: higher sun light intensity, no wind and no rain. At these days, the photocatalytic reaction will be more pronounced.

\section{Pilot Project in Antwerp}

An important issue is the conversion of the results obtained in the laboratory to real applications. In order to see the influence of photocatalytic pavements in "real conditions", a first pilot section of $10.000 \mathrm{~m}^{2}$ of photocatalytic pavement blocks was constructed in 2004-2005 on the parking lanes of a main axe in Antwerp [2]. Figure 5 depicts a view of the parking lane, where the photocatalytic concrete pavement blocks have been applied. Only the wearing layer (upper 5-6 mm) of the blocks contains anatase $\mathrm{TiO}_{2}$ mixed in the mass of the concrete layer. The exact composition could not be given by the manufacturer (Marlux, Tessenderlo, Belgium) at that time in view of confidentiality. In spite of the fact that the surface applied on the Leien of Antwerp is quite important, one has to notice the relatively small width of the photocatalytic parking lanes in comparison with the total street: $2 \times 4.5 \mathrm{~m}$ versus a total width of $60 \mathrm{~m}$.

Figure 5. Separate parking lanes at the Leien of Antwerp with photocatalytic pavement blocks.

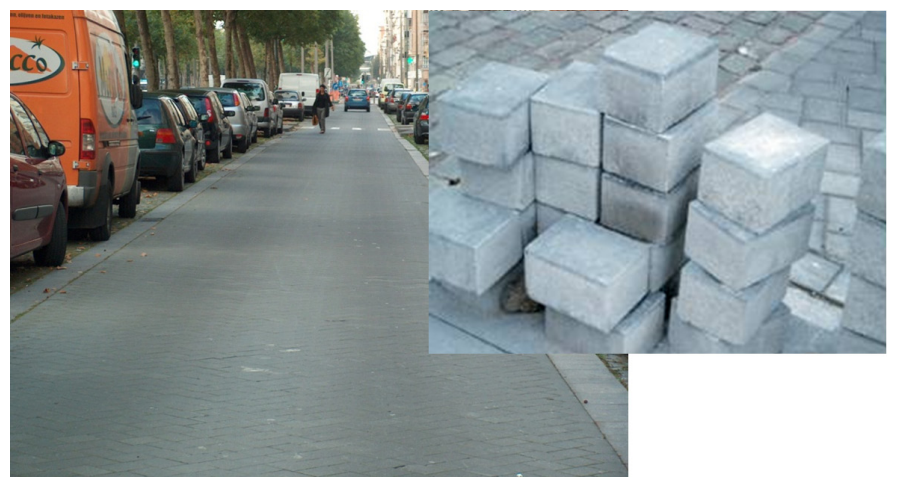

In order to check the durability of the photocatalytic efficiency, pavement blocks were taken from the lane after different periods of exposure and measured in the laboratory with and without washing of the surface. Some of the results are presented in Figure 6. They indicate a good durability of the efficiency towards $\mathrm{NO}_{x}$ abatement. The deposition of pollutants on the surface leads to a decrease in efficiency which can be regained after washing. Recently repeated measurements in 2010 indicate that even after more than five years of service life, the photocatalytic efficiency of the pavers is still present [22].

Besides the tests in the lab, on site measurements were also carried out. Since no reference measurements without photocatalytic material (prior to the application) exist, the interpretation of these results is rather difficult. Especially the influence of traffic, wind speed, light intensity and relative humidity are playing an important role. Detailed results can be found in [2]. In brief, the field measurements suggested a decrease in $\mathrm{NO}_{x}$ concentration at the sites with photocatalytic materials, where a levelling out of the pollution peaks is visible. In any case, precaution has to be taken with the interpretation of data since these results are momentary and limited over time. However, at least, they gave an indication of the efficiency of the photocatalytic pavement materials in situ, and a basis to work on for future applications. 
Figure 6. $\mathrm{NO}_{x}$ reduction measured on two pavement blocks, before (hatched) and after (colored) washing the surface, taken on different locations (house nr. 30, 35, 37, 42, 48, 53) and at different times at the Amerikalei in Antwerp.

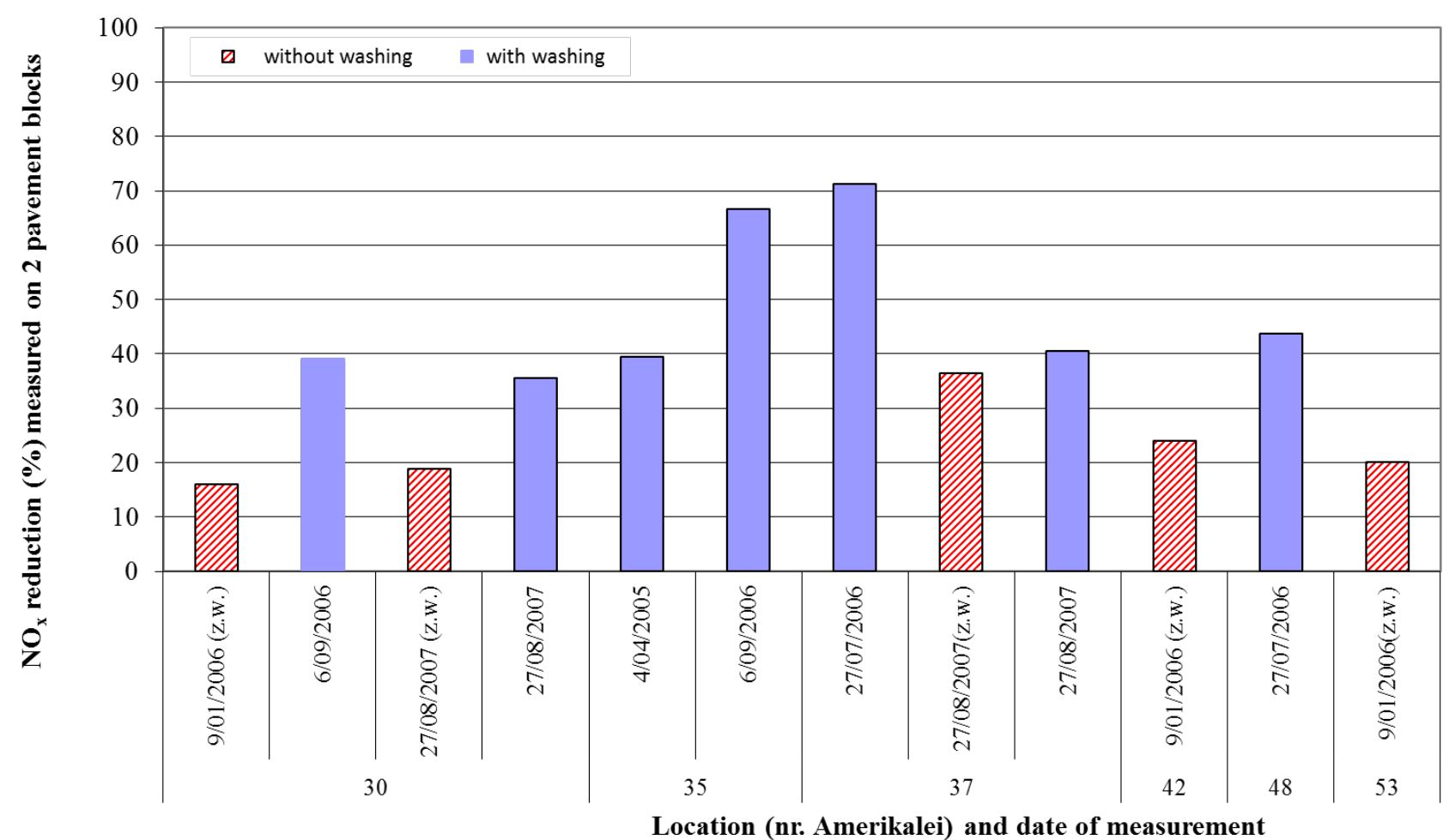

\section{Recent Photocatalytic Applications in Belgium}

Since the first application in Antwerp (2004-2005), much progress has been made within the photocatalytic research area. Newer, better and more efficient materials are constantly being developed, and action is more and more broadened also to visible light responsive materials [17]. This also led to new trial applications in which people have tried to establish the relation between the results in the laboratory and the real effect on site, see e.g., [23-25]. In this section an overview is given of two such recent projects in Belgium which were implemented in collaboration with the BRRC.

\subsection{Life+ Project PhotoPAQ}

The European Life+ funded project PhotoPAQ [18] was aimed at demonstrating the usefulness of photocatalytic construction materials for air purification purposes in an urban environment. Eight partners from five different European countries participated in the project.

In this framework, an extensive three-step field campaign was organized in the Leopold II tunnel in Brussels, from June 2011 till January 2013 [26,27]. A photocatalytic cementitious coating material (TX Active ${ }^{\circledR}$ white Skim Coat from CTG Italcementi Group) was applied on the side walls and roof (total area of about $2700 \mathrm{~m}^{2}$ ) of a tunnel section of about $160 \mathrm{~m}$ in length in one of the tunnel tubes directing to the city center. The air-purifying product was activated by a dedicated UV lighting system (including Supratec "HTC 241 R7s" light bulbs from Osram, see Figure 7). More details can be found in $[26,27]$. 
Figure 7. Application of the photocatalytic product and installation of the UV lamps in the Leopold II tunnel in Brussels, in the framework of PhotoPAQ.
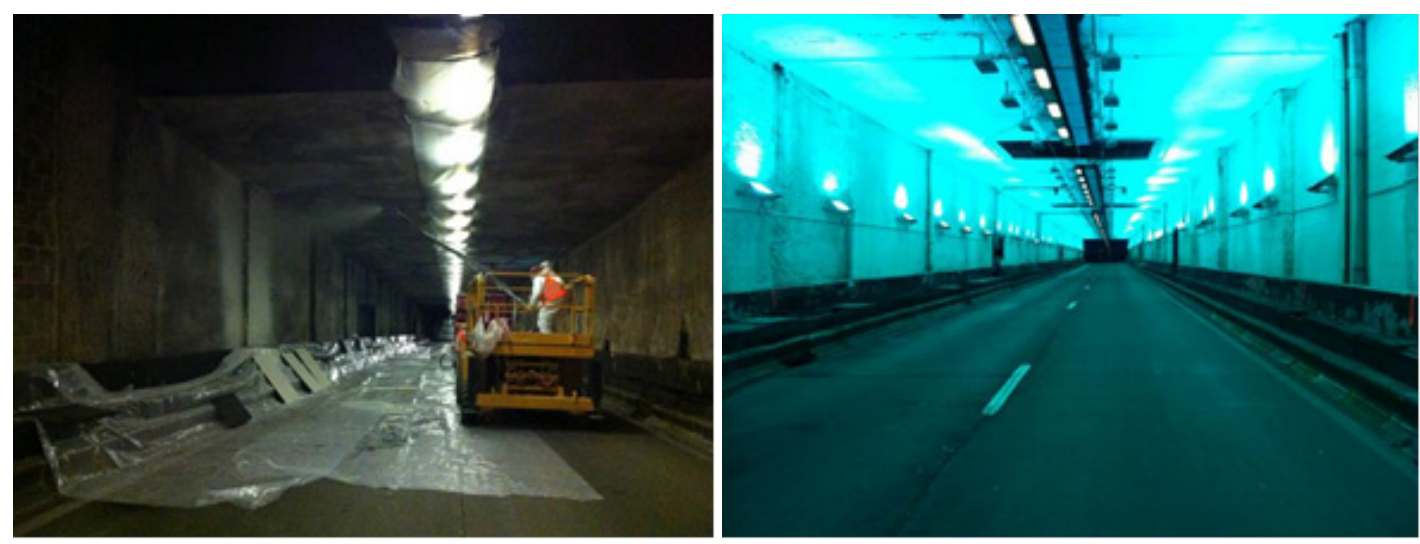

Possible advantages of purifying the tunnel air may be, obviously, cleaner air to breathe, with a potentially reduced need of ventilation, but also (and maybe mainly) a reduction of the pollution impact of tunnel exhaust on the city air quality. During the field campaigns, the effect of the photocatalytic coating on the air pollution (including $\mathrm{NO}_{x}$, VOC's, particulate matter, $\mathrm{CO}$, etc.) inside the tunnel section was rigorously assessed.

The PhotoPAQ consortium mobilized a large panel of up-to-date instrumentations, installed in the tunnel for several weeks, aiming at characterizing the levels of pollution in this section of the Leopold II tunnel, with and without the air-purifying product (Figure 8).

Figure 8. Full characterization of the air quality inside the tunnel test section during the PhotoPAQ campaigns.

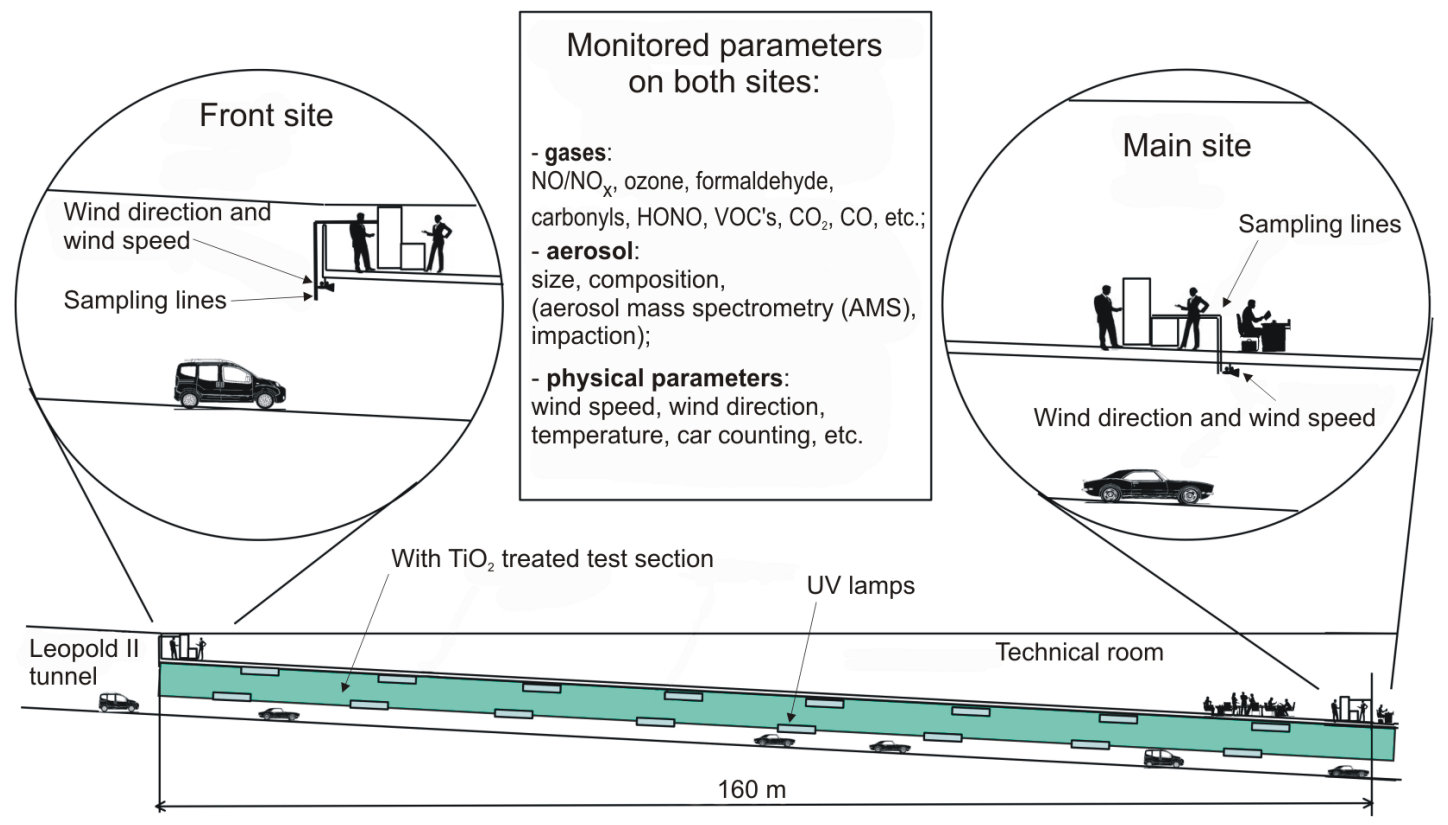

However, in contrast to first estimations based on laboratory studies, the results indicated no observable reduction of the pollution level, i.e., the reduction of nitrogen oxides $\left(\mathrm{NO}_{x}\right.$, one of the major traffic related air pollutants) is below $2 \%$, which is the experimental uncertainty of the measurements. 
A severe de-activation of the photocatalytic material was observed inside the highly trafficked and strongly polluted Leopold II tunnel. In conjunction, final UV lighting intensity (only $2 \mathrm{~W} / \mathrm{m}^{2} \mathrm{UV}-\mathrm{A}$ ) was below the targeted values (above $4 \mathrm{~W} / \mathrm{m}^{2}$ ), which led to too low levels for proper activation inside the polluted tunnel environment. Another negative condition was the high wind speed (up to $3 \mathrm{~m} / \mathrm{s}$ ) inside the tunnel, limiting the contact time between pollutants and the active surface. Finally, January 2013 turned out to be an unusually wintry period causing cold and humid conditions inside the tunnel, with relative humidity ranging from $70 \%$ to $90 \%$, which also reduces the activity of the photocatalytic material as shown before. Thus, all these issues together resulted in a reduction of the activity of the photocatalytic surfaces inside the harsh environment of the Leopold II tunnel, by a factor of 10 compared to the theoretical expectations. More details about the set-up and results of these extensive field campaigns inside the Leopold II tunnel are presented elsewhere [26,27].

Nevertheless, combining the knowledge gained during these campaigns and the laboratory based investigations performed by the PhotoPAQ consortium, numerical simulations (with the commercially available general purpose Computational Fluid Dynamics code ANSYS CFX ${ }^{\circledR}$ ) were performed in order to estimate the possible best-case abatement of pollutants.

These calculations indicate that, under the best case scenario (proper level of UV light intensity higher than $4 \mathrm{~W} / \mathrm{m}^{2}$, relative humidity below $50 \%$, and limited pollution to avoid passivation), the reduction of the $\mathrm{NO}_{x}$ concentration may be expected to attain:

- $\pm 3 \%$ for the $160 \mathrm{~m}$ long test section;

- $\pm 12 \%$ for the entire Leopold II tunnel ( $c a .3 \mathrm{~km})$, if not affected by ventilation.

Despite the fact that the results were not as expected, the Leopold II field campaigns conducted by the PhotoPAQ team proved to be a unique real world and fully comprehensive assessment of the effect of photocatalytic air-purifying (road) construction materials on air pollution inside a tunnel environment. Based on the extensive experimental data set gathered and numerical model calculations, a valuable tool for extrapolation can be provided to estimate the expected pollution reduction in other urban tunnel sites, also for use by non-experts [18].

\subsection{INTERREG Project ECO ${ }_{2}$ PROFIT}

The broad environmental sustainability project $\mathrm{ECO}_{2}$ PROFIT dealt with the reduction of the emission of greenhouse gases and sustainable production of energy on industrial estates in the frontier area between Flanders and Holland. To reach these goals, several tangible demonstration projects were carried out on industrial sites in Belgium and the Netherlands. BRRC was involved in two such projects: "Den Hoek 3" in Wijnegem and "Duwijckpark" in Lier (both near Antwerp). Here, the regional development agency POM Antwerp was aiming to use a double layered concrete for the road construction, with recycled concrete aggregates in the bottom layer and photocatalytic materials $\left(\mathrm{TiO}_{2}\right)$ in the top layer, using photoactive cements and/or coatings. That way, air purifying and $\mathrm{CO}_{2}$ reducing concrete roads could be built which are both innovating and energy efficient.

For these recently completed applications (2010-2011) BRRC was asked to set-up an elaborate testing program in the lab to help optimize the air purifying performance of the top layer, without interfering with other properties of the concrete (workability, strength, durability etc.). In the 
construction site of Wijnegem (Den Hoek 3), it was opted to use an exposed aggregates surface finish (with grain size between 0 and $6.3 \mathrm{~mm}$ ) on the top layer for reasons of noise reduction and comfort of the road user. For the site in Lier (Duwijckpark) a brushed surface finishing was chosen to have more active cement at the surface. Indeed, the type of surface finishing and/or treatment of the pavement can have an effect on the photocatalytic efficiency, as shown in Figure 9 for three types of surface finishing: exposed aggregates, smooth (formwork side) and sawn surface. The results show that the exposed aggregates surface performs equally well as the smooth, formwork surface, but not as good as a sawn surface. This is the result of the combined action of less photoactive cement at the surface and a higher surface porosity (higher specific surface), two competing effects which in the end yield the final efficiency shown in Figure 9.

Figure 9. Effect of surface treatment on photocatalytic efficiency (only one type of "less" active product in mass).

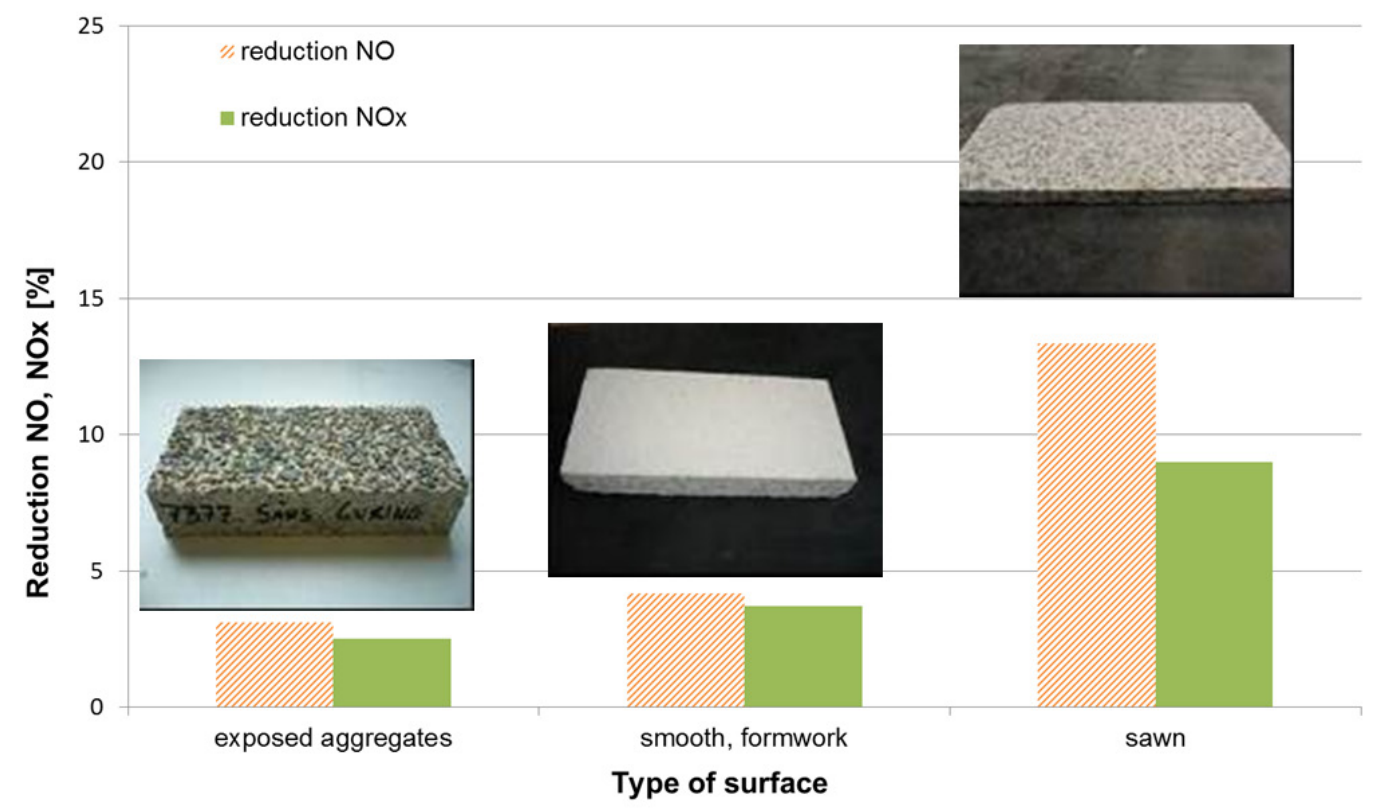

For the application of photocatalytic materials in a concrete road (and in general for any other type of application) a fundamental choice can be made between: mixing in the mass (e.g., $\mathrm{TiO}_{2}$ in cement) and/or spraying on the surface (suspension of $\mathrm{TiO}_{2}$ ). The former has the advantage of a more durable action since the $\mathrm{TiO}_{2}$ will continuously be present, even after wearing of the top layer. On the other hand, the initial cost will be higher (higher $\mathrm{TiO}_{2}$ content, necessity for double layered concrete) and only the $\mathrm{TiO}_{2}$ at the surface will be active. In contrast, dispersing at the surface of a $\mathrm{TiO}_{2}$ solution will provide a more direct action, and a lower initial cost (e.g., "ordinary" cement). In this case however, the longevity of the photocatalytic action could be questioned because of loss of adhesion to the surface in time. This fundamental choice was also investigated within the research program, together with the influence of several other parameters [28].

The effect of a curing compound for instance-generally applied to protect the young concrete against desiccation in Belgium and placed directly after concreting or after exposing the aggregates at the surface in case of denudation - is illustrated in Figure 10. From this, it appears the curing compound will initially inhibit the photocatalytic reaction, most likely because it is shielding off the "active" 
components from the pollutants in the air. Consequently, it is probable that the curing must disappear from the surface, i.e., under influence of traffic or weathering, before the $\mathrm{TiO}_{2}$ will reach its optimal air purifying performance. In case of a photocatalytic spray coating, this also means that it is best to apply the $\mathrm{TiO}_{2}$ dispersion some months after the curing compound to have the most durable effect. Alternatively, the exposed aggregates concrete can be covered with a plastic sheet to prevent dehydration (in case the concrete surface is denuded).

Figure 10. (a) Application of curing compound on fresh concrete, and (b) Effect of curing compound on photocatalytic efficiency (different samples A-D, with photocatalytic $\mathrm{TiO}_{2}$ in mass and/or applied as dispersion, with and without curing compound).

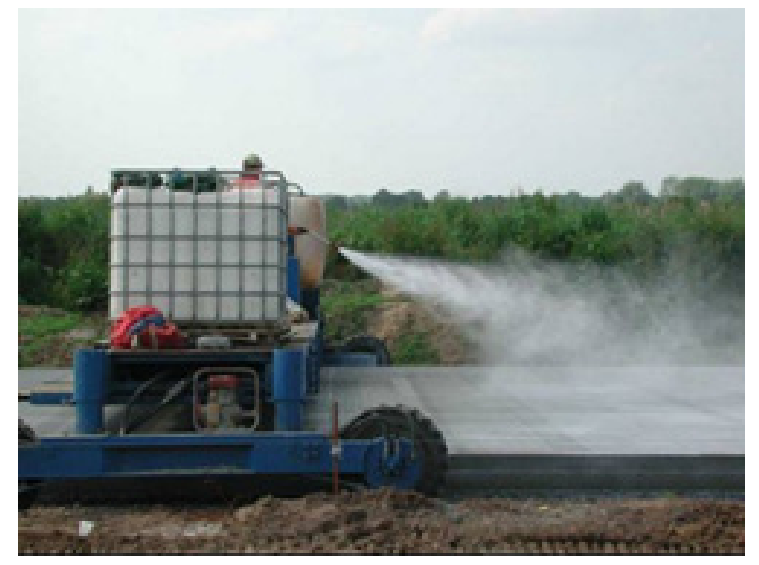

(a)

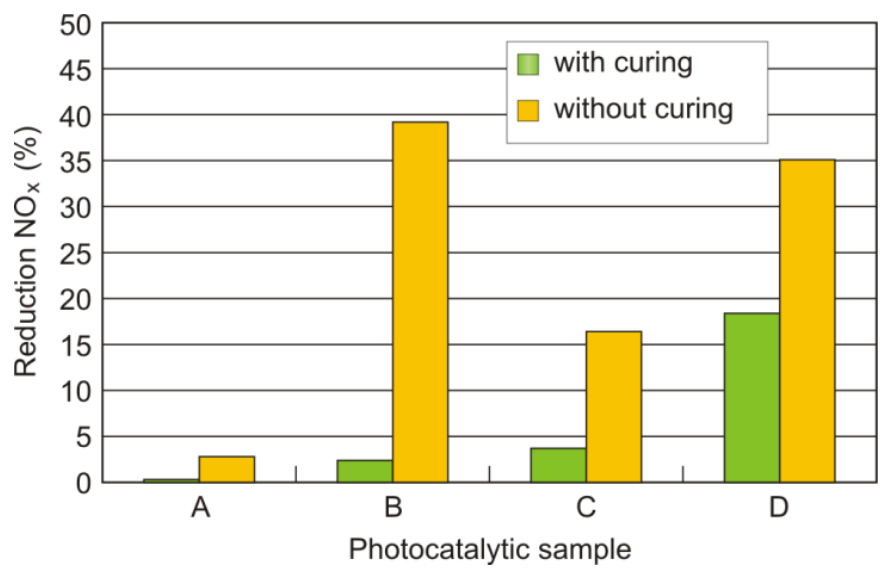

(b)

More detailed results of the laboratory research can be found in [28] and [29]. Based on the findings and the optimization of the concrete composition, a proper selection of photocatalytic materials and application techniques could be made, for the construction of double layered, photocatalytic concrete roads on the industrial zone "Den Hoek 3" in Wijnegem.

\section{Double Layered Concrete at "Den Hoek 3" in Wijnegem}

The concrete pavement of the industrial zone in Wijnegem has been constructed between the 15 th and 18th of March 2011. The concrete was placed in two layers, wet-in-wet, with an interval time of approximately 1 hour. The bottom layer had a thickness of $180 \mathrm{~mm}$, while the top layer was designed to be $50 \mathrm{~mm}$. For the concrete of the bottom layer, $57 \%$ of the coarse aggregates were replaced by recycled concrete aggregates. For the top layer with $\mathrm{TiO}_{2}$, commercially available white cement with $4 \% \mathrm{TiO}_{2}$ pre-mixed (by weight) was applied (CBR, Belgium, Heidelberg Cement Group). Two slip form pavers were used to place the concrete. As can be seen in Figure 11a, the color of the top layer is much lighter, due to the use of white cement and the presence of the $\mathrm{TiO}_{2}$ (about $0.8 \mathrm{wt} \%$ of the top layer).

More information on the concrete composition, the execution and the results obtained in the lab as well as on site can be found in [28] and [29]. Besides the photocatalytic concrete roads, photocatalytic pavement blocks were also used for the bicycle lanes, parking spaces and foot paths.

Since this was a completely new industrial zone, it was not possible to have measurements on site before putting the photocatalytic concrete in place. An overview of the project is given in Figure 12. Immediately after concreting, a retarding agent was sprayed on the surface to be able to wash out the top 
surface after $24 \mathrm{~h}$, to create an exposed aggregates surface finish (see Figure 11b). In order to prevent dehydration of the concrete during the first days, some parts of the road have been treated with curing compound; the other zones were covered with a plastic sheet. This way, the influence of the curing compound on the short and long term photocatalytic efficiency could be investigated.

Figure 11. (a) Construction of double layered concrete pavement at industrial zone "Den Hoek 3" in Wijnegem; (b) Detail of exposed aggregates surface finish of the top layer.

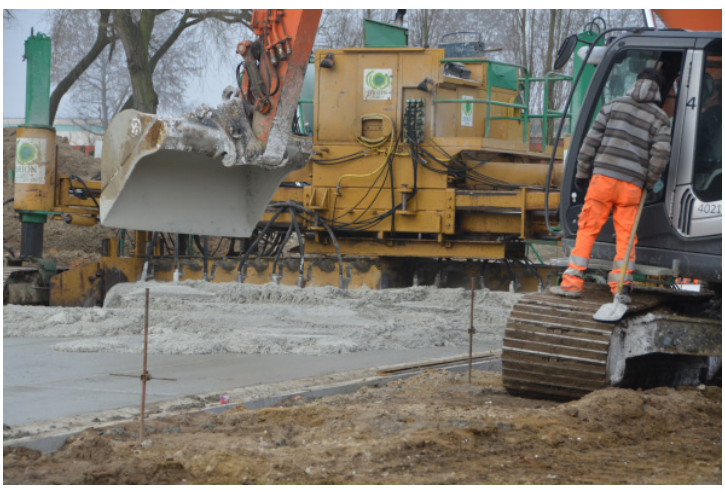

(a)

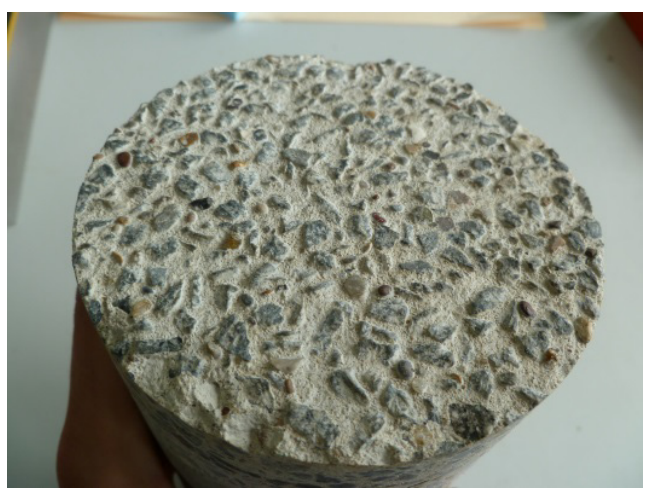

(b)

Figure 12. (a) Situation plan of the new industrial zone "Den Hoek 3" in Wijnegem, Belgium (Google Maps); (b) "On site” testing of photocatalytic efficiency.

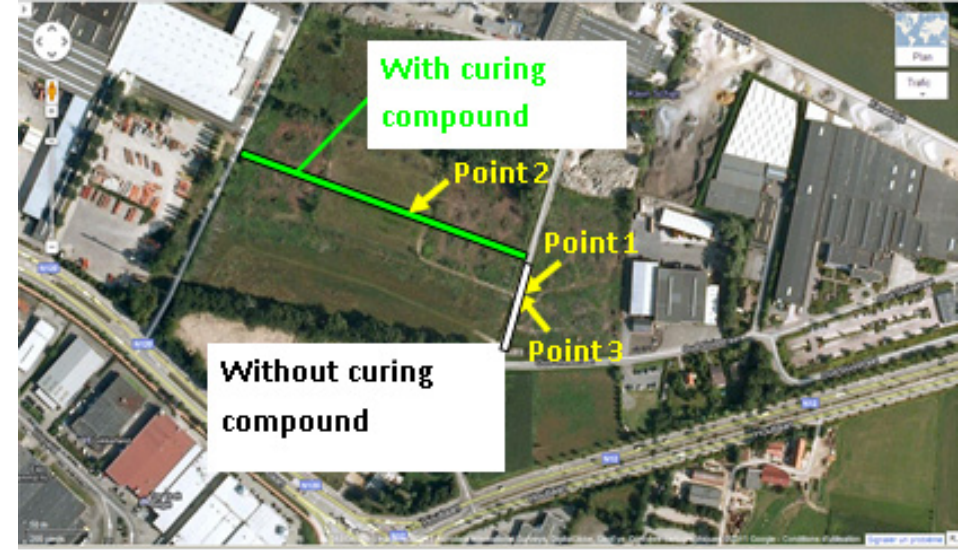

(a)

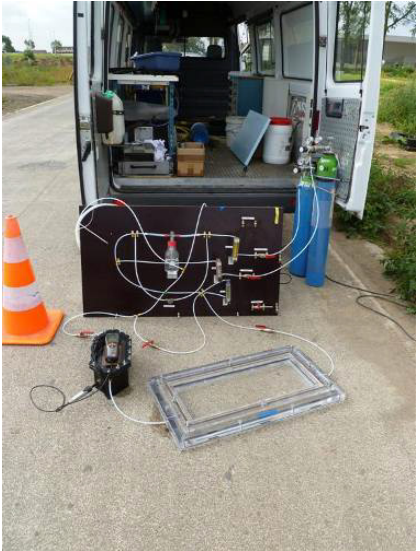

(b)

The photocatalytic efficiency of the top layer was measured in two ways: in the laboratory on cores taken from the surface at the places indicated in Figure 12a, and "on site" with a special measuring set-up, shown in Figure 12b. This "on site" test is developed to evaluate the photocatalytic properties of the concrete pavement over time and to compare the different sites (with and without curing, for example). It does not measure the overall purification of the air around the pavement but enables to measure the durability of the photocatalytic efficiency.

The set-up consists of a Plexiglas frame, screwed air-tight on the test surface (concrete pavement), and is covered with a UV-transparent glass lid. The input NO-concentration (1 ppmv), relative humidity $(50 \% \mathrm{RH})$ and air flow $(3 \mathrm{~L} / \mathrm{min})$ are taken similar to the laboratory set-up. However, the total area covered by the box is somewhat larger $\left(700 \times 300 \mathrm{~mm}^{2}\right)$ to have a representative surface, and natural (varying!) sunlight is used in first instance to activate the surface. First results of the measurements on 
site are given in Figures 13 and 14, and were collected 5 months after the placement of the concrete (August 2011) at the places indicated in Figure 12a (points 1 and 2).

Figure 13. $\mathrm{NO}_{x}$ concentration measured at the outlet for zone with curing compound, 5 months after concreting (point 2, August 2011).

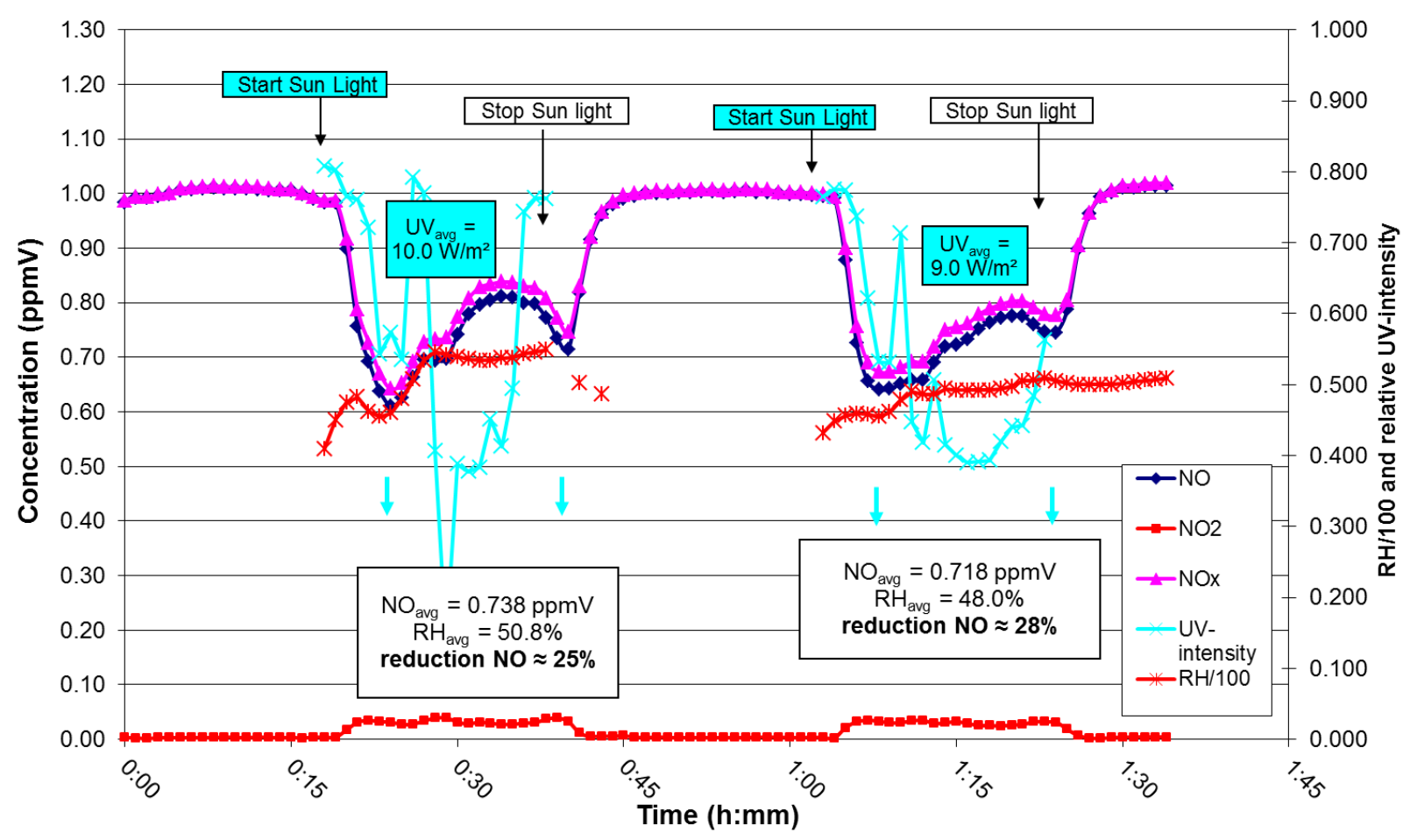

Figure 14. $\mathrm{NO}_{x}$ concentration measured at the outlet for zone without curing compound, 5 months after concreting (point 1, August 2011).

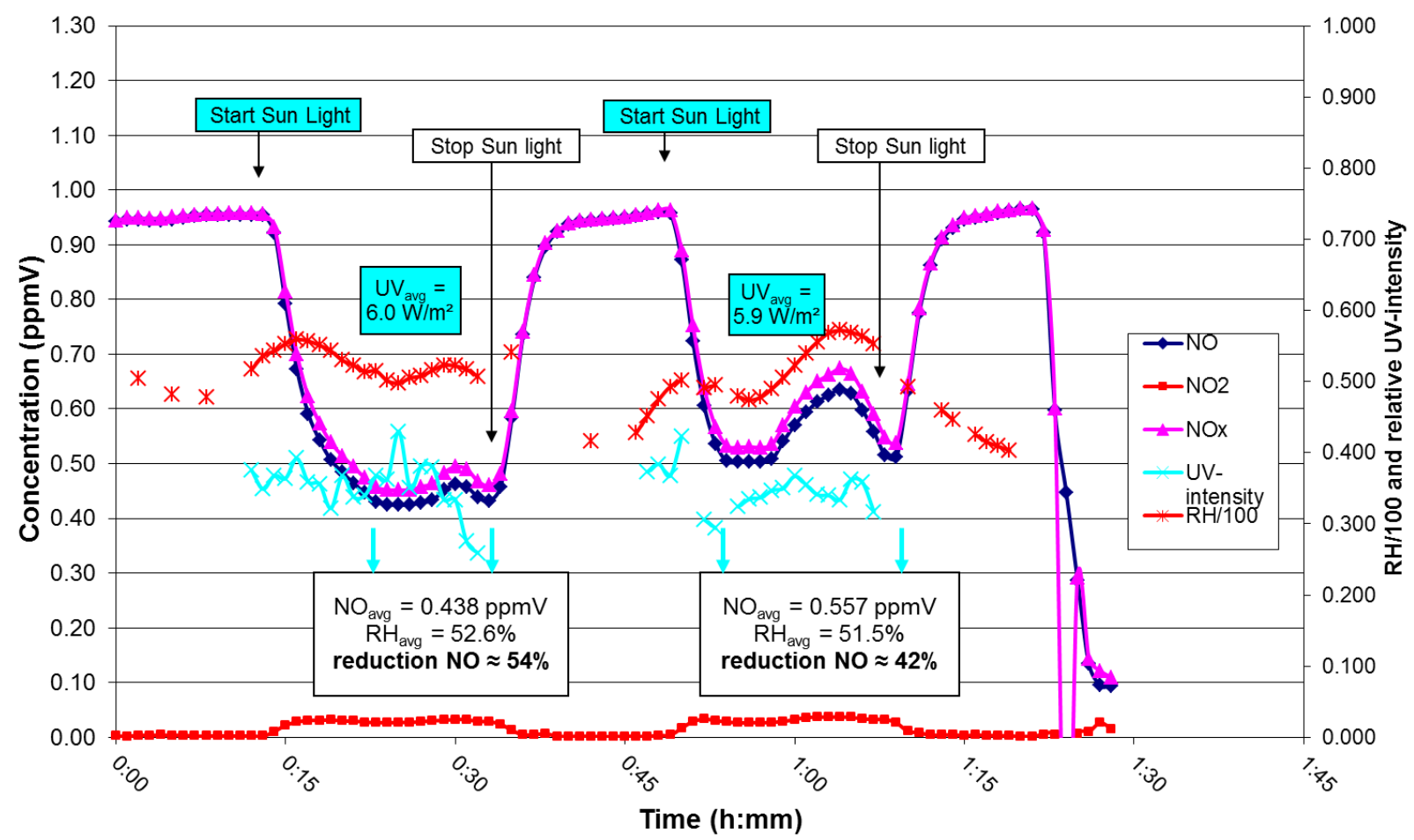


First of all, the results shown in Figures 13 and 14 indicate a large influence of the relative humidity (red curves). The $\mathrm{NO}_{x}$ abatement is lower when the relative humidity increases and higher when $\mathrm{RH}$ decreases again. The influence of the sun light intensity (measured through the UV intensity, light blue lines) is also visible, but on a different scale: variations over a shorter period of time do not influence the $\mathrm{NO}_{x}$ concentration immediately; it is the average sun light intensity over a longer period that is determining the attained $\mathrm{NO}_{x}$ abatement for the photocatalytic process.

Furthermore, the reduction in NO concentration is significantly lower for the zone with curing compound, indicating it is still (slightly) inhibiting the reaction: average reduction of $27 \%$ (with curing) versus $48 \%$ (without curing). Nevertheless, the effect of applying a curing compound on the fresh concrete (to protect against dehydration) seems to diminish over time. These results obtained on site (year 2011) are also in line with the results obtained in the laboratory, taking into account the difference in surface, relative humidity and light intensity [28].

In order to correctly compare the results between the lab and the field, the photocatalytic activity for $\mathrm{NO}_{x}$ ( = sum of $\mathrm{NO}$ and $\mathrm{NO}_{2}$ ) is expressed in terms of the photocatalytic deposition velocity in $[\mathrm{m} / \mathrm{h}$ ] under the assumption of a first order uptake kinetics and negligible transport limitations from the gas phase to the solid surface [30]:

$$
k_{R}=\ln \left(c_{0} / c_{t}\right) F / A
$$

where $c_{0}$ and $c_{t}$ are the reactant concentration at the inlet and exit of the photo-reactor, respectively. In fact, this parameter refers to a first order reaction rate coefficient independent of the applied flow rate $F$ and the active surface $(A)$ to volume ratio of the used reactor (lab or on site). In the lab work [28], average values for the $\mathrm{NO}_{x}$ deposition velocity $k_{R, N O x}$ of 0.25 and $0.70 \mathrm{~m} / \mathrm{h}$ were obtained with and without curing compound respectively, which is in nice agreement with the results on site for 2011 (see further in Table 1).

The measurements on site are also repeated over time in order to see the influence of ageing and traffic on the photocatalytic efficiency. Recent measurements performed in the summer of 2012 for instance, are shown in Figure 15. Here, measurements were performed using an external UV-lamp $\left(10 \mathrm{~W} / \mathrm{m}^{2}\right)$ as well as natural sunlight to activate the photocatalyst present in the pavement. It appears the activity under sun light is somewhat higher compared to the UV lamp only. This could be due to the fact that the applied $\mathrm{TiO}_{2}$ (in the active cement) is also partially active under visible light and/or is excited by the shorter UV wavelengths (UV-B, UV-C) present in the sun spectrum.

On the other hand, the measurement of the UV-intensity comprised in the sun light could be erroneous because of the radiometer used here. This is only calibrated for specific UV-A lamps (between 300 and $400 \mathrm{~nm}$ ) applied in the geometry of the lab set-up which differs substantially from these exterior tests. The activity observed under natural, varying sun light though, is still very interesting from the view point of practical application. The use of the external UV-lamp with constant light intensity in turn, allows making a more absolute comparison of the photocatalytic activity between different zones and for different times.

In any case, the results of Figure 15 reveal already that the efficiency of this kind of photocatalytic application $\left(\mathrm{TiO}_{2}\right.$ integrated in the cement) appears to decrease in time: on average $34 \%$ NO-reduction (after 17 months) versus $48 \%$ (after 5 months). Possible causes could reside in the covering of the $\mathrm{TiO}_{2}$ at 
the surface by dirt, the detachment of the $\mathrm{TiO}_{2}$ from the surface or the deposition of products from chemical reactions which can take place at the surface.

Figure 15. $\mathrm{NO}_{x}$ concentration measured at the outlet for zone without curing compound, 17 months after concreting (point 3, August 2012).

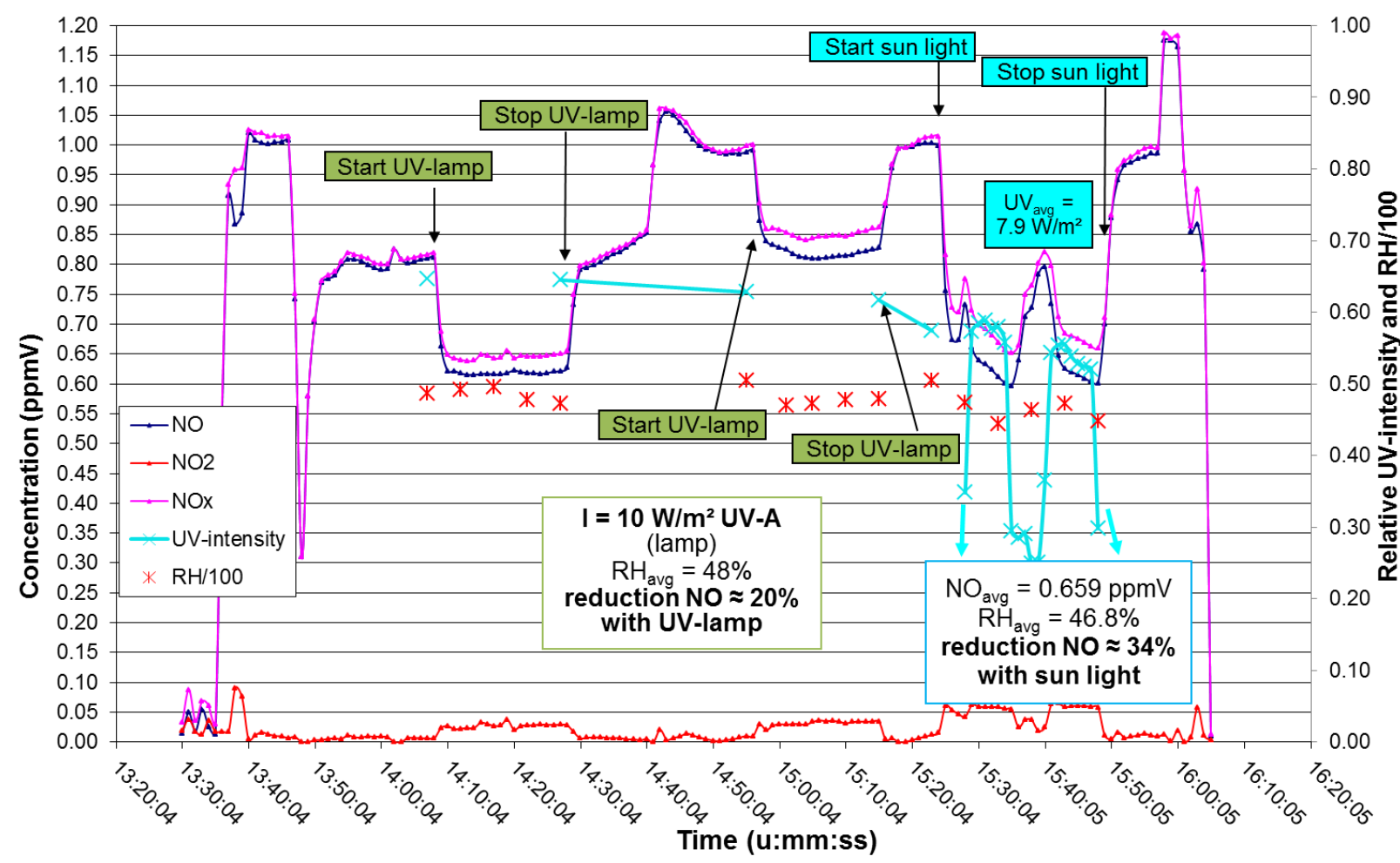

In this respect, in October 2012 an aqueous $\mathrm{TiO}_{2}$ dispersion (Eoxolit ${ }^{\circledR}$ consisting of a mixture of two different types of $\mathrm{TiO}_{2}$ particles with a total concentration of $40 \mathrm{~g} / \mathrm{L} \mathrm{TiO}$ ) was also applied on the surface in some parts of the roads on the industrial zone in Wijnegem, as shown in Figure 16a, for the purpose of comparative measurements. In total four different zones were considered:

- Zone $1=$ double layered concrete $\left(0 / 6.3 \mathrm{~mm}\right.$ on top) without $\mathrm{TiO}_{2}$;

- Zone 2 = single layered concrete $(0 / 20 \mathrm{~mm})$ without $\mathrm{TiO}_{2}$;

- Zone 3 = double layered concrete with $\mathrm{TiO}_{2}$ (active cement) and without curing compound;

- Zone 4 = double layered concrete with $\mathrm{TiO}_{2}$ (active cement) and with curing compound.

The photocatalytic dispersion was applied with a dose of approximately $1 \mathrm{~L}$ per $5 \mathrm{~m}^{2}$ on a total of $800 \mathrm{~m}^{2}$, followed by spraying of a hydrophobic product for optimal functioning of the coating (manufacturers' guidelines). Important to mention however, is the fact that at the time of application there was a severe pollution with soil and dirt at the surface of the pavement in some zones due to the presence of a grinding installation plant at the site. This most certainly had an impact on the efficiency of the $\mathrm{TiO}_{2}$ suspension (see further). Subsequently, provisional controls of the photocatalytic efficiency have been carried out to check the separate action of the two types of photoactive materials (mass and dispersion), and to further assess the durability of the air purifying performance. Most recent measurements on the site in Wijnegem were performed in the summer of 2013, at the measurement points (1-9) indicated in Figure 16b. All results obtained up till now (2011-2013) are summarized in Table 1. 
Figure 16. (a) Application of photocatalytic dispersion on part of the roads at industrial zone "Den Hoek 3" (October 2012); (b) Localization of measurement points for “on site" testing (Google Maps).

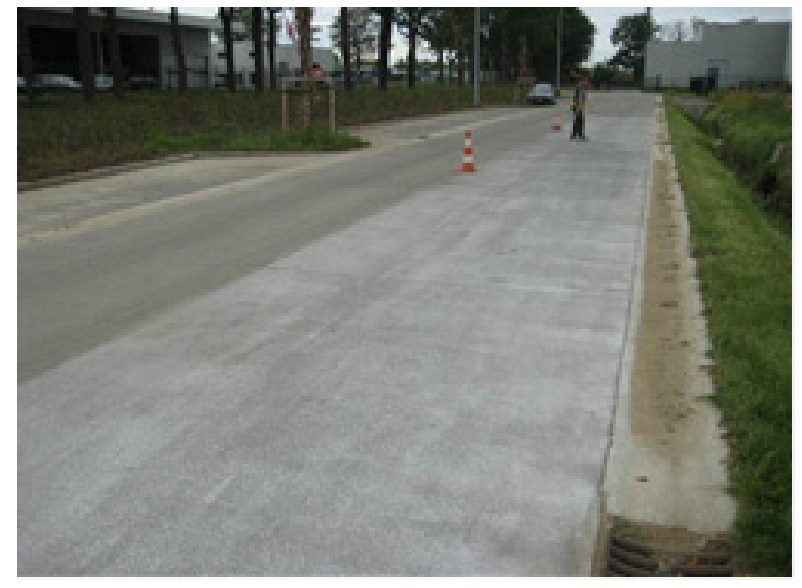

(a)

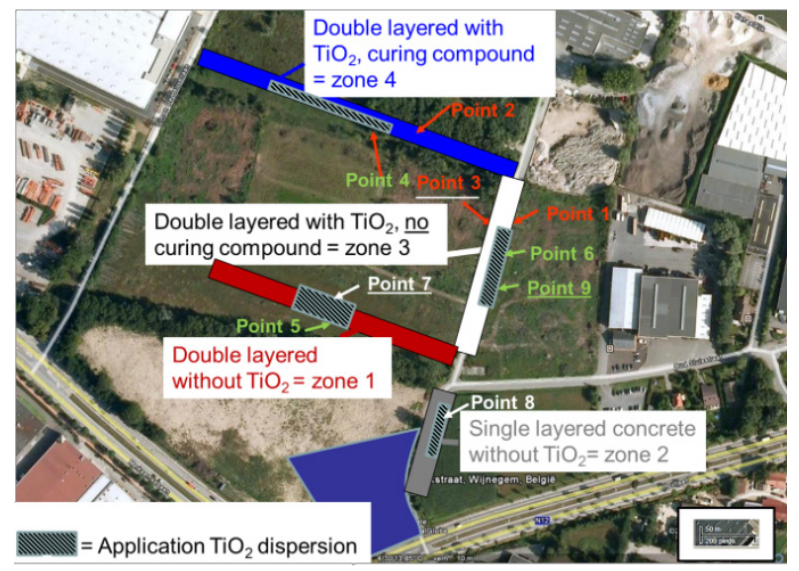

(b)

Table 1. Summary of results in time for photocatalytic activity measured on site in Wijnegem.

\begin{tabular}{|c|c|c|c|c|c|}
\hline \multirow{3}{*}{ Zone } & \multicolumn{5}{|c|}{$k_{R, N O}\left(k_{R, N O x}\right)[\mathrm{m} / \mathrm{h}]$} \\
\hline & \multicolumn{3}{|c|}{ Sun light } & \multicolumn{2}{|c|}{ UV-lamp $\left(10 \mathrm{~W} / \mathrm{m}^{2}\right)$} \\
\hline & 2011 & 2012 & 2013 & 2012 & 2013 \\
\hline $\begin{array}{l}\text { 4: with curing compound, } \\
\text { active cement (point } 2,4 \text { ) }\end{array}$ & $\begin{array}{c}0.30 \\
(0.26) \\
\end{array}$ & $\begin{array}{c}0.09 \\
(0.07) \\
\end{array}$ & - & $\begin{array}{c}0.06 \\
(0.04) \\
\end{array}$ & - \\
\hline $\begin{array}{l}\text { 3: without curing compound, } \\
\text { active cement (point } 1 \text { and } 3 \text { ) }\end{array}$ & $\begin{array}{c}0.70 \\
(0.66)\end{array}$ & $\begin{array}{c}0.39 \\
(0.34)\end{array}$ & $\begin{array}{c}0.38 \\
(0.28)\end{array}$ & $\begin{array}{c}0.21 \\
(0.19)\end{array}$ & $\begin{array}{c}0.22 \\
(0.18)\end{array}$ \\
\hline $\begin{array}{l}\text { 4: with curing, active cement } \\
+\mathrm{TiO}_{2} \text { dispersion (point } 4 \text { ) }\end{array}$ & - & - & $\begin{array}{c}0.82 \\
(0.62)\end{array}$ & - & $\begin{array}{c}0.28 \\
(0.22)\end{array}$ \\
\hline $\begin{array}{l}\text { 3: without curing, active cement } \\
+\mathrm{TiO}_{2} \text { dispersion (points } 6 \text { and 9) }\end{array}$ & - & - & $\begin{array}{c}0.27 \\
(0.20)\end{array}$ & - & $\begin{array}{c}0.21 \\
(0.15)\end{array}$ \\
\hline $\begin{array}{l}\text { 1: double layered, no active cement } \\
+\mathrm{TiO}_{2} \text { dispersion (point 7) }\end{array}$ & - & - & $\begin{array}{c}0.32 \\
(0.27) \\
\end{array}$ & - & $\begin{array}{c}0.15 \\
(0.13)\end{array}$ \\
\hline $\begin{array}{l}\text { 2: single layered, no active cement } \\
+\mathrm{TiO}_{2} \text { dispersion (point } 8 \text { ) }\end{array}$ & - & - & $\begin{array}{c}0.14 \\
(0.13) \\
\end{array}$ & - & $\begin{array}{c}0.08 \\
(0.07) \\
\end{array}$ \\
\hline
\end{tabular}

First of all, when comparing the measurements on the surface of the pavement at points 1 and 3 (cf. Figure 16b) in 2013 with these of 2012, a very similar result can be noticed: a photocatalytic deposition velocity for $\mathrm{NO}_{x}$ of $c a .0 .2 \mathrm{~m} / \mathrm{h}$ under UV light. This indicates that the decreasing trend in photocatalytic activity for the concrete with "active" cement (see evolution 2011-2012) seems to be stabilized in 2013.

Furthermore, the measured efficiency for points 1 and 3 (in 2013) appears to differ little or nothing with the one for points 6 and 9, with application of the photocatalytic coating $\left(\mathrm{TiO}_{2}\right.$ dispersion) on the pavement surface. Here, the $\mathrm{TiO}_{2}$ dispersion did not produce a significant added value (yet) in terms of photocatalytic air purifying action. Only for point 4 (active cement with curing compound, after application of $\mathrm{TiO}_{2}$ dispersion) one can notice a strong improvement of the photocatalytic efficiency (deposition velocity of $c a .0 .8 \mathrm{~m} / \mathrm{h}$ for NO under sun light and nearly $0.3 \mathrm{~m} / \mathrm{h}$ under UV ). Possibly, the 
pollution of the surface at the time of application has played an important part causing the adhesion of the coating to be far from optimal.

For points 7 and 8 (concrete without active cement, but with $\mathrm{TiO}_{2}$ dispersion on the surface), the activity is not significantly better either (or even less) compared to the "pure" concrete with active cement. In addition, point 8 (single layered concrete $0 / 20$ ) reveals much smaller photocatalytic reactivity than point 7 (double layered concrete with top layer 0/6.3): deposition velocity of $0.08 \mathrm{~m} / \mathrm{h}$ versus $0.15 \mathrm{~m} / \mathrm{h}$ for NO reduction under UV. This probably has to do with the stronger adhesion of the coating on the surface of the finer $(0 / 6.3)$ double layered concrete compared to the coarser $(0 / 20)$ single layered concrete.

Finally, a measurement on site was also performed for the newly constructed pavements at the industrial zone in Lier, which have a different surface finishing as illustrated in Figure 17a. The results of this measurement, 20 months after construction, are shown in Figure $17 \mathrm{~b}$.

Figure 17. (a) Double layered photocatalytic concrete pavement with brushed surface finish at industrial zone "Duwijckpark" in Lier; (b) $\mathrm{NO}_{x}$ concentration measured at the outlet for the site in Lier (active cement + curing compound), 20 months after concreting (August 2013).

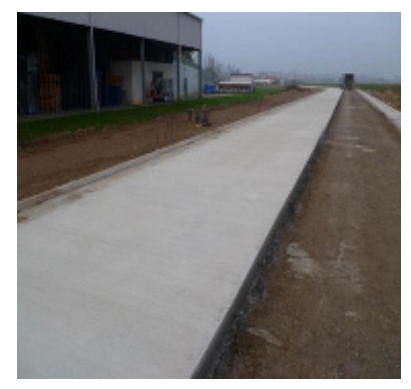

(a)

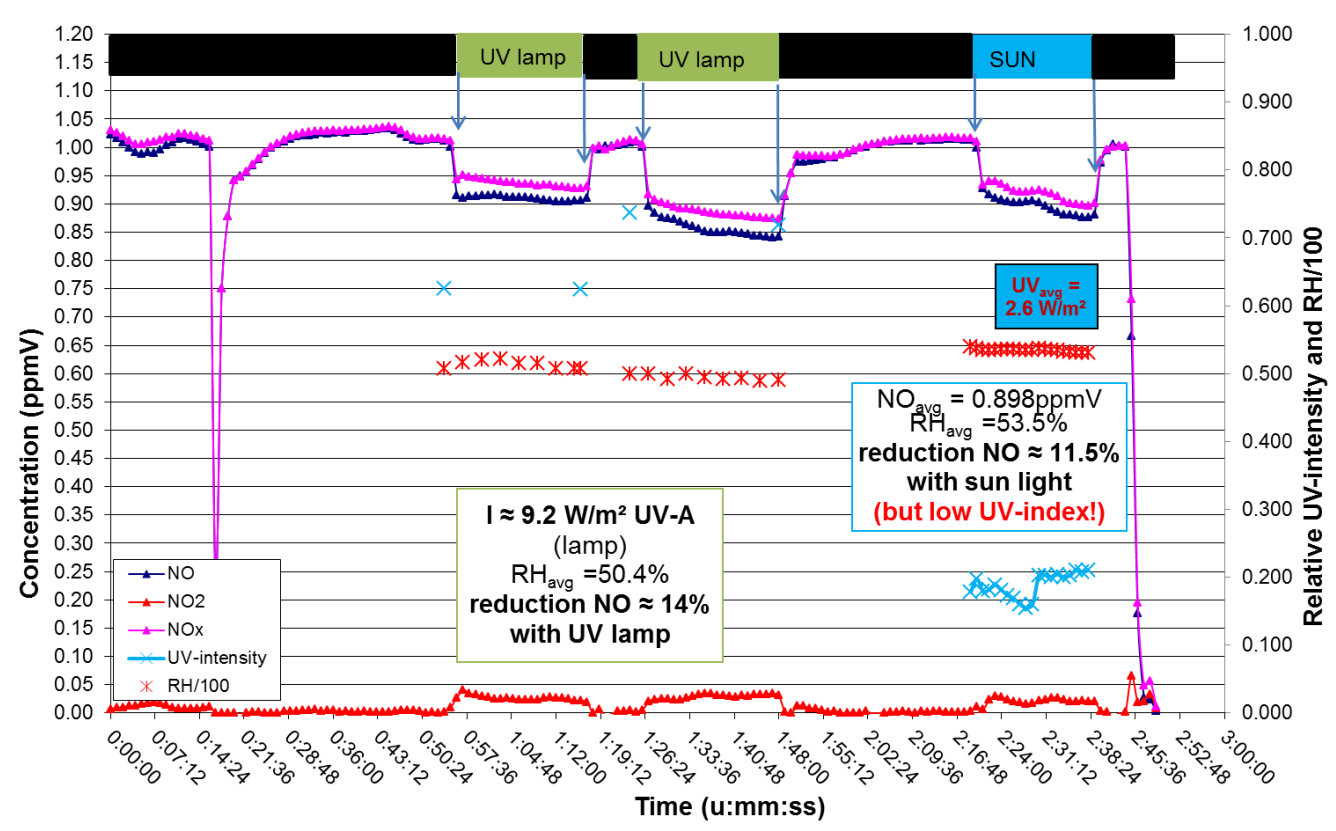

(b)

In comparison with the measurements of Wijnegem in 2013 (see Table 1), a slightly lower photocatalytic reaction is observed in Lier, which among others is due to the use of a curing compound (for the brushed surface) and the lower $\mathrm{TiO}_{2}$ content (less cement used). However, if we make the comparison with the zone with curing compound in Wijnegem ( $c f$. point 4 in zone 4) measured in 2012 (17 months after construction), a significantly better result under UV light is obtained in Lier: deposition velocity for NO of $0.14 \mathrm{~m} / \mathrm{h}$ in Lier versus $0.06 \mathrm{~m} / \mathrm{h}$ in Wijnegem. This higher activity probably has to do with the brushed surface finish instead of exposing the aggregates ( $c f$. Figure 9). In any case, these measurements confirm the photocatalytic action 20 months after construction of the concrete pavement. 


\section{Conclusions and Perspectives}

Photocatalytic $\left(\mathrm{TiO}_{2}\right.$ containing) paving materials with the potential of reducing air pollution by traffic are being used more frequently on site in horizontal as well as in vertical applications, also in Belgium. Laboratory results indicate a good efficiency towards the abatement of $\mathrm{NO}_{x}$ in the air by using these innovative materials. The durability of the photocatalytic action also remains mostly intact, though regular cleaning (by rain) of the surface is necessary. The relative humidity (RH) is an important parameter, which may reduce the efficiency on site. If the RH is too high, the water will be adsorbed at the surface and prevent the reaction with the pollutants.

The translation from the laboratory results to the "on-site efficiency" is still a difficult and critical factor, because of the great number of parameters involved. Hence, there is still a need for large scale applications to demonstrate the effectiveness of photocatalytic materials in "real life" and evaluate the durability of the air purifying action, such as the European Life+ project PhotoPAQ and the industrial zones "Den Hoek 3" in Wijnegem en "Duwijckpark" in Lier. These recent applications in Belgium show already some interesting results.

It seems the use of photocatalytic cement-based coatings inside road tunnels is not mature for application on a large scale yet. From the experience gained during the Leopold II tunnel campaigns in Brussels, recommendations for the proper use of these innovative materials can be made though, such as:

- Optimized coating application for low surface roughness and minimizing dust adsorption;

- High UV light intensity levels in the order of magnitude of $10 \mathrm{~W} / \mathrm{m}^{2}$;

- Low average relative humidity of tunnel air $(\leq 60 \%)$;

- High enough photocatalytic activity, with threshold values defined from lab studies;

- Low average wind speed $(<2 \mathrm{~m} / \mathrm{s})$ in the tunnel for increased reaction time of pollutants;

- High surface to volume ratio (smaller sized tunnel tubes).

For the double layered photocatalytic concrete pavements using active cement, an efficiency comparable to the one measured in the laboratory is obtained initially; though it seems to decrease somewhat in time due to dirt build-up and other deposits on the surface, the air purifying action has stabilized after more than two years (2011-2013). Application of a curing compound-to protect the fresh concrete against desiccation - initially strongly reduces the photocatalytic activity and also has an impact on the long term. Use of a plastic sheet to protect the young concrete is therefore recommended. Furthermore, the exposed aggregates technique is not ideal for the photocatalytic efficiency since in this case a lot of aggregates are present at the surface and the $\mathrm{TiO}_{2}$ is only present in the paste. The application of a brushed surface finish could lead to a better result.

Use of a photocatalytic coating $\left(\mathrm{TiO}_{2}\right.$ dispersion) on the surface of the concrete pavement does not produce an added value for the air purifying action compared to mixing in the mass, despite the good results in the laboratory. This probably has to do with the loss of adhesion in time and the filthiness of the surface at the time of application. Possibly, the coating is partially washed away with the dirt. In addition, better results are obtained on the finer, double layered concrete $(0 / 6.3)$ than for the coarser, single layered concrete $(0 / 20)$ which could be due to the better adhesion of the coating on the surface. 
Durability of the photocatalytic action in time (for products mixed in the mass and/or applied on the surface) and optimization of the adhesion of photo-active coatings on the concrete surface, are topics that need to be investigated further.

Finally, the best results will be achieved by modeling the environment, validating the models by measurements on site, followed by an implementation of the different influencing parameters to assess the real life effect. One must bear in mind that photocatalytic applications are not effective everywhere; "good" contact between the airborne pollutants and the active surface is crucial and factors such as wind speed and direction, street configuration and pollution sources all play a very important role.

\section{Acknowledgements}

The authors wish to thank IWT Flanders (Institute for the Promotion of Innovation by Science and Technology in Flanders), FPS Economy (Federal Public Service), Life+ and EFRO (European Union), INTERREG and the Ministry of the Brussels-Capital Region-Brussels Mobility for the (financial) support of the different projects.

\section{Author Contributions}

E.L.B and A.B. both coordinated and supervised the different research projects involving photocatalytic applications; E.L.B. prepared the manuscript. All authors read and approved the manuscript.

\section{Conflicts of Interest}

The authors declare no conflict of interest.

\section{References}

1. European Commission. EU Energy and Transport in Figures, Statistical Pocketbook; Publications Office of the European Union: Brussels, Belgium, 2011.

2. Beeldens, A. Air purification by pavement blocks: Final results of the research at the BRRC. In Proceedings of Transport Research Arena-TRA 2008, Ljubljana, Slovenia, 21-24 April 2008.

3. Directive 2008/50/EC of the European Parliament and of the Council on ambient air quality and cleaner air for Europe. Off. J. Eur. Union 2008, L152:1-L152:44.

4. Chen, J.; Poon, C. Photocatalytic construction and building materials: From fundamentals to applications. Build. Environ.2009, 44, 1899-1906.

5. Renz, C. Lichtreaktionen der Oxyde des Titans, Cers und der Erdsäuren. Helv. Chim. Acta 1921, 4, 961-968.

6. Fujishima, A.; Honda K. Electrochemical photolysis of water at a semiconductor electrode. Nature 1972, 238, 37-38.

7. Fujishima, A.; Rao, T.N.; Tryk, D.A. Titanium dioxide photocatalysis. J. Photochem. Photobiol. C 2000, 1, 1-21.

8. Sopyan, I.; Watanabe, M.; Murasawa, S.; Hashimoto, K.; Fujishima, A. An efficient $\mathrm{TiO}_{2}$ thin-film photocatalyst: Photocatalytic properties in gas-phase acetaldehyde degradation. J. Photochem. Photobiol. A 1996, 98, 79-86. 
9. Cassar, L.; Pepe, C. Paving Tile Comprising an Hydraulic Binder and Photocatalyst Particles. EP-Patent 1600430 A1, 1997.

10. Murata, Y.; Tawara, H.; Obata, H.; Murata, K. $\mathrm{NO}_{x}$-Cleaning Paving Block. EP-Patent 0786283 A1, 1996.

11. Ohama, Y.; Van Gemert, D. Application of Titanium Dioxide Photocatalysis to Construction Materials; Springer: Dordrecht, The Netherlands, 2011.

12. Saubere Luft Durch Pflastersteine Clean Air by Airclean ${ }^{\circledR}$. Available online: http://www.ime.fraunhofer.de/content/dam/ime/de/documents/AOe/2009_2010_Saubere\%20Luft $\% 20 d u r c h \% 20$ Pflastersteine_s.pdf (accessed on 25 July 2014).

13. Dillert, R.; Stötzner, J.; Engel, A.; Bahnemann, D.W. Influence of inlet concentration and light intensity on the photocatalytic oxidation of nitrogen(II) oxide at the surface of Aeroxide ${ }^{\circledR} \mathrm{TiO}_{2} \mathrm{P}_{25}$. J. Hazard. Mater. 2012, 211-212, 240-246.

14. Laufs, S.; Burgeth, G.; Duttlinger, W.; Kurtenbach, R.; Maban, M.; Thomas, C.; Wiesen, P.; Kleffmann, J. Conversion of nitrogen oxides on commercial photocatalytic dispersion paints. Atmos. Environ. 2010, 44, 2341-2349.

15. Devahasdin, S.; Fan, C.; Li, J.K.; Chen, D.H. $\mathrm{TiO}_{2}$ photocatalytic oxidation of nitric oxide: Transient behavior and reaction kinetics. J. Photochem. Photobiol. A 2003, 156, 161-170.

16. Ballari, M.M.; Yu, Q.L.; Brouwers, H.J.H. Experimental study of the $\mathrm{NO}$ and $\mathrm{NO}_{2}$ degradation by photocatalytically active concrete. Catal. Today 2011, 161, 175-180.

17. Fujishima, A.; Zhang, X. Titanium dioxide photocatalysis: Present situation and future approaches. Comptes Rendus Chim. 2006, 9, 750-760.

18. PhotoPAQ (2010-2014) Life+ Project. Available online: http://photopaq.ircelyon.univ-lyon1.fr/ (accessed on 25 July 2014).

19. ISO 22197-1:2007 Fine Ceramics (Advanced Ceramics, Advanced Technical Ceramics) -Test Method for Air-Purification Performance of Semi Conducting Photocatalytic Materials-Part 1: Removal of Nitric Oxide; International Standards Organization (ISO): Geneva, Switzerland 2007.

20. CEN Technical Committee 386 "Photocatalysis" Business Plan-(internet) Draft BUSINESS PLAN CEN/TC386 PHOTOCATALYSIS. Available online: http://standards.cen.eu/BP/653744.pdf (accessed on 28 July 2014).

21. Hüsken, G.; Hunger, M.; Brouwers, H.J.H. Experimental study of photocatalytic concrete products for air purification. Build. Environ. 2009, 44, 2463-2474.

22. Beeldens, A.; Boonen, E. Photocatalytic applications in Belgium, purifying the air through the pavement. In Proceedings of the XXIVth World Road Conference, Mexico City, Mexico, 26-30 September 2011.

23. Maggos, Th.; Plassais, A.; Bartzis, J.G.; Vasilakos, Ch.; Moussiopoulos, N.; Bonafous, L. Photocatalytic degradation of $\mathrm{NO}_{x}$ in a pilot street canyon configuration using $\mathrm{TiO}_{2}$-mortar panels. Environ. Monit. Assess. 2008, 136, 35-44.

24. Gignoux, L.; Christory, J.P.; Petit, J.F. Concrete roadways and air quality-Assessment of trials in Vanves in the heart of the Paris region. In Proceedings of the 12th International Symposium on Concrete Roads, Sevilla, Spain, 13-15 October 2010.

25. Guerrini, G.L. Photocatalytic performances in a city tunnel in Rome: $\mathrm{NO}_{x}$ monitoring results. Constr. Build. Mater. 2012, 27, 165-175. 
26. Boonen, E.; Akylas, V.; Barmpas, F.; Boréave, A.; Bottalico, L.; Cazaunau, M.; Chen, H.; Daële, V.; De Marco, T.; Doussin, J.F.; et al. Photocatalytic de-pollution in the Leopold II tunnel in Brussels, Part I: Construction of the field site. Constr. Build. Mater. 2014, Submitted.

27. Gallus, M.; Akylas, V.; Barmpas, F.; Beeldens, A.; Boonen, E.; Boréave, A.; Bottalico, L.; Cazaunau, M.; Chen, H.; Daële, V.; et al. Photocatalytic de-pollution in the Leopold II tunnel in Brussels, Part II: $\mathrm{NO}_{x}$ abatement results. Constr. Build. Mater. 2014, Submitted.

28. Boonen, E.; Beeldens, A. Photocatalytic roads: From lab testing to real scale applications. Eur. Transp. Res. Rev. 2013, 5, 79-89.

29. Beeldens, A.; Boonen, E. A double layered photocatalytic concrete pavement: A durable application with air-purifying properties. In Proceedings of 10th International Conference on Concrete Pavements (ICCP), Quebec, Canada, 8-12 July 2012.

30. Ifang, S.; Gallus, M.; Liedtke, S.; Kurtenbach, R.; Wiesen, P.; Kleffmann, J. Standardization methods for testing photo-catalytic air remediation materials: Problems and solution. Atmos. Environ. 2014, 91, 154-161.

(C) 2014 by the authors; licensee MDPI, Basel, Switzerland. This article is an open access article distributed under the terms and conditions of the Creative Commons Attribution license (http://creativecommons.org/licenses/by/3.0/). 